\title{
Manual de los Reglamentos del Agua en Florida: Ley Para el Control de la Contaminación del Aire y el Agua de Florida ${ }^{1}$
}

\author{
Michael T. Olexa, Luke D'Isernia, Laura Minton, Dulcy Miller y Sara Corbett ${ }^{2}$
}

\section{Prefacio}

Este manual esta diseñado para proporcionar un resúmen autorizado, exacto y actual de las principales leyes Federales y de Florida que están directa o indirectamente relacionadas a la agricultura. Este manual debe proveer una vista general de los muchos derechos y responsabilidades que tienen los agricultores y propietarios de tierras agrícolas bajo las leyes tanto Federal como de Florida, así como también la información de los contactos apropiados para obtenerla con más detalle. Sin embargo, el lector debe estar advertido de que algunas partes de esta publicación podrían volverse obsoletas en cualquier momento, debido a que las leyes, reglas administrativas, y decisiones de la corte, sobre las cuales se basa este manual, se encuentran bajo revisión constante. Algunos detalles de las leyes citadas no se mencionan, debido a limitaciones de espacio.
Este manual es distribuido con la aclaración de que los autores no intentan proporcionar una asesoría legal o profesional, y que la información contenida aquí no debe ser considerada como un sustituto de asesoría profesional. En este manual, no se incluye toda la información para llevar a cabo el cumplimiento de las leyes Federales y de Florida y los reglamentos que rigen la protección del agua. Por estas razones, el uso de estos materiales por cualquier persona, constituyen un acuerdo para mantener libre de perjuicios a los autores, al Servicio de Extensión Cooperativa de Florida, al Instituto de los Alimentos y Ciencias Agrícolas y a la Universidad de Florida por reclamos de responsabilidad, daños o gastos provenientes de quien sea, por haberse referido o basado en la información contenida en este manual.

1. Este es el documento EDIS FE090, una publicación de Food and Resource Economics Department, Florida Cooperative Extension Service, Institute of Food and Agricultural Sciences, University of Florida, Gainesville, FL. Publicado Noviembre 2006. Por favor visite la página electrónica de EDIS en http://edis.ifas.ufl.edu.

2. Michael T. Olexa, profesor, Food and Resource Economics Department y director, Agricultural Law Center, University of Florida, Gainesville, FL, y presidente, Agricultural Law Committee, The Florida Bar; Luke D'Isernia, alumni, Levin College of Law, University of Florida, Gainesville, FL; Laura Minton, abogado, Dean, Mead, Egerton, Bloodworth, Capouano y Bozarth, PA, Orlando FL; Dulcy Miller, abogado, Foley and Lardner, LLP, Orlando, FL; y Sarah Corbett, abogado, Florida Second District Court of Appeal, Lakeland, FL. La traducción del ingles al español estuvo a cargo de Filiberto Reyes-Villanueva. 


\section{Vista General}

La Legislatura de Florida emitió en 1994 la Ley para el Control de la Contaminación del Aire y el Agua de Florida (LCCAAF), en reconocimiento que la contaminación del aire y el agua de Florida es una amenaza para la salud y bienestar publico; es perjudicial para la vida silvestre, el agua y el aire son dañinos para los usos domésticos, agrícolas, industriales y otros.

El propósito de la LCCAAF es para conservar, proteger y mejorar la calidad de las aguas de Florida para una variedad de propósitos, incluyendo los suministros de agua publica y la preservación de la vida silvestre, y para llevar a cabo y mantener los niveles de calidad del aire que protegerá no solo la salud y seguridad humana, sino también la vida de las plantas y animales así como propiedades para promover el desarrollo social y económico de Florida.

\section{¿Quién Hace Cumplir la LCCAAF?}

El DPA es el principal encargado de hacer cumplir la LCCAAF y es responsable por el desarrollo de sus reglas y leyes. La LCCAAF requiere que el DPA haga procedimientos de transcripciones disponibles para toda la LCCAAF.

\section{¿Cuáles Son los Deberes del DPA, Según la LCCAAF?}

Acompañado al cumplimiento de la ley, el DPA tiene múltiples deberes conforme la LCCAAF incluyendo los deberes para:

- Aprobar y desarrollar planes actualizados y de largo plazo para proporcionar el control a la calidad del aire y el agua y disminuir la contaminación.

- Asegurar los servicios científicos, técnicos administrativos, de investigación y operativos necesarios de otras agencias estatales mediante un acuerdo entre las agencias, etc.

- Adoptar un programa completo para la prevención, disminución y control de la contaminación del aire y las aguas de Florida, y para la revisión y modificación de este programa según sea necesario.

- Tomar y examinar muestras del aire y agua para determinar los niveles de la calidad de los mismos en todo el estado de Florida.

- Exigir a las personas involucradas en operaciones que puedan resultar en contaminación, que archiven reportes que pueden contener información relacionada a la tasa y periodo de emisión, composición y concentración de contaminantes.

- Establecer un sistema de requerimientos para un permiso para la operación, construcción o expansión de cualquier instalación que pueda ser fuente de contaminación del aire o el agua, y estipule la emisión y revocación de tales permisos.

- Consultar con cualquier persona, una propuesta para construir, instalar, o también adquirir un dispositivo o sistema para control de la contaminación; dicha consulta es respecto a la efectividad de tal dispositivo o sistema, o el problema de contaminación respecto a la fuente, dispositivo o sistema.

- Establecer reglas que ayuden a definir la categoría especial de cuerpos de agua dentro del estado, conocidas como Aguas Sobresalientes de Florida, las cuales son dignas de especial protección debido a sus atributos naturales.

- Coordinar el programa de aguas de lluvia de Florida.

- Ejercitar los deberes, poderes y responsabilidades requeridas de los estados según la Ley del Aire Limpio (LAL).

Para una lista completa de deberes, poderes y requerimientos del DPA según la LCCAAF, por favor contacte al DPA.

\section{Fuente}

Capitulo 403, de los Estatutos de Florida, Secciones 403.011 al 403.0611 


\section{Agradecimientos}

Los autores agradecen al personal de las agencias estatales y federales por su tiempo y asesoría en la preparación de este manual. Los autores agradecen especialmente a Richard Budell del Office of Agricultural Water Policy of the Florida Department of Agriculture and Consumer Services por el apoyo económico para el desarrollo de esta publicación. 